\title{
ZnO Thin-Film Transistor Grown by rf Sputtering Using Carbon Dioxide and Substrate Bias Modulation
}

\author{
Junghwan Kim, ${ }^{1,2}$ Jun Meng, ${ }^{1,3}$ Donghoon Lee, ${ }^{1}$ Meng Yu, ${ }^{1}$ Dukyean Yoo, ${ }^{1}$ \\ Doo Won Kang, ${ }^{4}$ and Jungyol Jo ${ }^{1}$ \\ ${ }^{1}$ Department of Electrical and Computer Engineering, Ajou University, Suwon 443-749, Republic of Korea \\ ${ }^{2}$ Materials and Structures Laboratory, Tokyo Institute of Technology, Yokohama 226-8502, Japan \\ ${ }^{3}$ Samsung Electronics, Giheung, Hwaseong 445-330, Republic of Korea \\ ${ }^{4}$ Smart Electronics Co., Ltd., Samdong-myeon, Ulsan 689-930, Republic of Korea \\ Correspondence should be addressed to Jungyol Jo; jungyol@ajou.ac.kr
}

Received 16 June 2014; Revised 23 September 2014; Accepted 22 October 2014; Published 11 November 2014

Academic Editor: Songwei Lu

Copyright (C) 2014 Junghwan Kim et al. This is an open access article distributed under the Creative Commons Attribution License, which permits unrestricted use, distribution, and reproduction in any medium, provided the original work is properly cited.

$\mathrm{ZnO}$ thin-film transistor (TFT) grown by $\mathrm{rf}$ magnetron sputtering in $\mathrm{Ar} / \mathrm{O}_{2}$ atmosphere shows inferior turn-off characteristics compared to $\mathrm{ZnO}$ TFT grown by other methods. We thought that reactions between $\mathrm{Zn}$ and $\mathrm{O}_{2}$ might produce defects responsible for the poor turn-off behavior. In order to solve this problem, we studied sputtering growth in $\mathrm{Ar} / \mathrm{CO}_{2}$ atmosphere at $450^{\circ} \mathrm{C}$. During sputtering growth, we modulated substrate $\mathrm{dc}$ bias to control ion supply to the substrate. After growth $\mathrm{ZnO}$ was annealed in $\mathrm{CO}_{2}$ and $\mathrm{O}_{2}$ gas. With these methods, our bottom-gate $\mathrm{ZnO}$ thin-film transistor showed $4.7 \mathrm{~cm}^{2} / \mathrm{Vsec}$ mobility, $4 \times 10^{6}$ on/off ratio, and $-2 \mathrm{~V}$ threshold voltage.

\section{Introduction}

$\mathrm{ZnO}$ has attracted much attention in applications of display devices due to many useful properties, such as high mobility, large exciton binding energy, and good transparency [1]. High mobility is important for data transmission speed in display devices, where amorphous silicon thin-film transistor (TFT) is currently employed. Amorphous $\mathrm{InGaZnO}_{4}$ (a-IGZO) TFT grown by sputtering showed better quality compared to ZnO TFT [2]. However, a-IGZO has a few problems for industry application, because it requires complicated, three-component sputtering targets which will increase manufacturing cost [3]. Simpler fabrication process and lower production cost make $\mathrm{ZnO}$ a strong candidate in display devices.

Various methods, such as radio-frequency (rf) sputtering $[4,5]$, molecular beam epitaxy (MBE) [6], pulsed-laser deposition (PLD) [7], metalorganic chemical vapor deposition (MOCVD) [8], and spray deposition [9] have been used to grow $\mathrm{ZnO}$. The advantage of sputtering is that it can deposit uniform films over a large area. Although much effort has been paid to improve quality of sputter grown $\mathrm{ZnO}$, it is still inferior to a-IGZO [10]. Because the same growth method gives different quality, it is necessary to understand intrinsic reasons of the lower quality in $\mathrm{ZnO}$.

There have been many reports on native point defects in $\mathrm{ZnO}$, for example, interstitial zinc, interstitial oxygen, and oxygen vacancy $[11,12]$. These defects can be the reason for the low quality of $\mathrm{ZnO}$. It is necessary to develop a growth method which can decrease the native point defects in $\mathrm{ZnO}$. In this work, we have focused on oxygen-related defects in $\mathrm{ZnO}$ and investigated the effects of growth atmosphere on $\mathrm{ZnO}$ TFT characteristics. Generally, sputtering in $\mathrm{Ar} / \mathrm{O}_{2}$ atmosphere has been used to grow $\mathrm{ZnO}$. However, we found that drain current in $\mathrm{Ar} / \mathrm{O}_{2}$ grown $\mathrm{ZnO}$ TFT is rather low compared to that grown in $\mathrm{Ar} / \mathrm{CO}_{2}$ atmosphere.

TFT should show good turn-off behavior as well as high mobility. Mobility always increases as the film thickness increases, but it is difficult to achieve good turn-off characteristics in a thicker layer TFT. Therefore, there is an optimum thickness for good TFT characteristics. When $\mathrm{ZnO}$ is grown by sputtering in $\mathrm{Ar} / \mathrm{O}_{2}$ atmosphere, turn-off 
TABLE 1: Growth conditions of samples.

\begin{tabular}{lcccc}
\hline Sample name & Ar flow $(\mathrm{sccm})$ & Oxidizer flow $(\mathrm{sccm})$ & rf power & Substrate bias \\
\hline A1 & 10 & $3 \mathrm{CO}_{2}$ & $60 \mathrm{~W}$ & $0 \mathrm{~V} /-70 \mathrm{~V}$ \\
A2 & 12 & $2 \mathrm{CO}_{2}$ & $70 \mathrm{~W}$ & $0 \mathrm{~V} /-70 \mathrm{~V}$ \\
$\mathrm{~B} 1$ & 8 & $4 \mathrm{O}_{2}$ & $60 \mathrm{~W}$ & $0 \mathrm{~V} /-70 \mathrm{~V}$ \\
$\mathrm{~B} 2$ & 12 & $2 \mathrm{O}_{2}$ & $70 \mathrm{~W}$ & $0 \mathrm{~V} /-70 \mathrm{~V}$ \\
C & 12 & $2 \mathrm{CO}_{2}$ & $70 \mathrm{~W}$ & $-70 \mathrm{~V}$ constant \\
\hline
\end{tabular}

behavior is not good. In order to solve this problem, we studied two approaches: (1) using $\mathrm{CO}_{2}$ as an oxidizer and (2) modulation of substrate dc bias. There have been reports that carbon is n-type dopants in $\mathrm{ZnO}[13,14]$. We hoped that the carbon in $\mathrm{CO}_{2}$ would increase electron density. Another advantage of using $\mathrm{Ar} / \mathrm{CO}_{2}$ is that $\mathrm{CO}_{2}$ may not produce $\mathrm{O}_{2}$ related "dumbbell-like" defects [15]. Erhart et al. showed that $\mathrm{O}_{2}$ could be incorporated in the $\mathrm{O}$ position of $\mathrm{ZnO}$ due to a strong oxygen-oxygen bond [15]. Carcia et al. have also reported that higher $\mathrm{O}_{2}$ partial pressure during sputtering produced lower quality $\mathrm{ZnO}$, because more oxygen adsorbed in the grain boundaries trapped free electrons [4].

When $\mathrm{CO}_{2}$ is used as an oxidizer in sputtering, $\mathrm{CO}_{2}$ would be dissociated to $\mathrm{CO}$ and $\mathrm{O}$, resulting in a mixture of $\mathrm{CO}_{2}, \mathrm{CO}$, and $\mathrm{O}$ in the chamber. In this case, the density of $\mathrm{O}_{2}$ would be negligible, and $\mathrm{ZnO}$ quality can be improved. We also expect that $\mathrm{CO}_{2}$ would have lower probability of creating defects than $\mathrm{O}_{2}$ does, because of the larger size and lower reactivity of $\mathrm{CO}_{2}$.

We wanted to grow $\mathrm{ZnO}$ at $450^{\circ} \mathrm{C}$, since film quality would be improved at a high growth temperature due to surface migration. However, at a high growth temperature it is more likely that unwanted chemical reactions occur at the substrate. Therefore, we applied dc substrate voltage to control source delivery to the substrate. Ionization of $\mathrm{CO}_{2}$ during sputtering will produce both positive and negative ions $\left(\mathrm{CO}_{x}{ }^{+}\right.$and $\left.\mathrm{CO}_{x}{ }^{-}\right)$[16]. The negative substrate voltage $(-70 \mathrm{~V})$ will attract positive ions $\left(\mathrm{Ar}^{+}, \mathrm{Zn}^{+}, \mathrm{CO}_{x}^{+}\right.$, and $\left.\mathrm{O}^{+}\right)$. The negative voltage will also prevent negative ions $\left(\mathrm{O}^{-}\right.$, $\mathrm{ZnO}^{-}$, and $\mathrm{CO}_{x}{ }^{-}$) colliding to the surface [17]. It is known that negative ions from the target are accelerated toward the substrate, causing radiation damage in the $\mathrm{ZnO}$ film. When $-70 \mathrm{~V}$ is turned off, positive ion supplies would decrease, and it will give $\mathrm{ZnO}$ films rest time to rearrange themselves at the high growth temperature. Among these various possibilities, we wanted to study which parameter makes any difference to the quality of $\mathrm{ZnO}$.

Another method we applied is postgrowth annealing. $\mathrm{ZnO}$ TFT characteristics were improved in various annealing environments, such as oxygen plasma [18], $\mathrm{H}_{2} \mathrm{O}$ plasma [19], and water vapor [20]. One of the important differences between $\mathrm{ZnO}$ and a-IGZO is that $\mathrm{ZnO}$ is polycrystalline with grain boundaries (GB) [21], while a-IGZO does not have any grain boundary because it is amorphous. GB in $\mathrm{ZnO}$ decreases current flow because extra voltage is required to cross the GB. In addition, gas adsorption on GB causes carrier density change and drift of TFT characteristics. By the annealing, we wanted to improve quality of $\mathrm{ZnO}$ associated

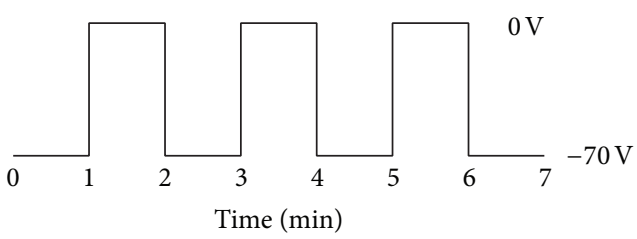

(a)

\begin{tabular}{|c|c|c|}
\hline S & & $\mathrm{D}$ \\
\hline \multicolumn{3}{|c|}{$\mathrm{ZnO}$} \\
\hline \multicolumn{3}{|c|}{ Si dioxide } \\
\hline & $\mathrm{p}+\mathrm{Si}$ & \\
\hline
\end{tabular}

(b)

FIgURE 1: (a) Substrate-voltage modulation during growth of samples $\mathrm{A}$ and $\mathrm{B} .-70 \mathrm{~V}$ was turned on and off at every $1 \mathrm{~min}$. (b) A schematic diagram of $\mathrm{ZnO}$ thin-film transistor (channel length $=$ $25 \mu \mathrm{m}$, width $=500 \mu \mathrm{m})$.

with $\mathrm{GB}$ and other defects. Annealing was performed in $\mathrm{CO}_{2}$ and $\mathrm{O}_{2}$ flow at $400^{\circ} \mathrm{C}$. At this temperature, we expect that $\mathrm{Zn}$ and $\mathrm{O}$ at imperfect configurations would rearrange to make perfect $\mathrm{ZnO}$.

\section{Experimental Details}

Our sputtering system (SCIEN Tech, Korea) has a 2-inch diameter $\mathrm{ZnO}$ target, with a $13.56 \mathrm{MHz}$ rf power source. Target-substrate distance was $6 \mathrm{~cm}$, and $\mathrm{rf}$ power during growth was $60 \mathrm{~W}$ or $70 \mathrm{~W}$. High vacuum was achieved by a diffusion pump. The pressure during growth was $1 \mathrm{~Pa}$, at $12 \mathrm{sccm}$ Ar flow and $2 \mathrm{sccm}$ oxidizer flow. $\mathrm{ZnO}$ films were grown on heavily doped p-type Si substrates $\left(10^{19} \mathrm{~cm}^{-3}\right)$ with a thermal oxide of $150 \mathrm{~nm}$ thickness. There is no pretreatment before $\mathrm{ZnO}$ growth. The substrate size is $5 \times$ $5 \mathrm{~cm}^{2}$, and growth temperature was $450^{\circ} \mathrm{C}$. Secondary ion mass spectroscopy (SIMS) profiles were measured in a timeof-flight mode using $25 \mathrm{keV} \mathrm{Ga}$ as an ion source. Five samples were compared, and details of growth conditions are shown in Table 1. Samples A1 and A2 were grown with $\mathrm{CO}_{2}$ oxidizer, while samples $\mathrm{B} 1$ and $\mathrm{B} 2$ were grown with $\mathrm{O}_{2}$ oxidizer. The effect of substrate voltage modulation was studied in sample C.

Figure 1(a) is a schematic diagram of the substrate voltage during growth of samples A and B. $-70 \mathrm{~V}$ was turned on and off at every $1 \mathrm{~min}$, and total growth time was $15 \mathrm{~min}$. 


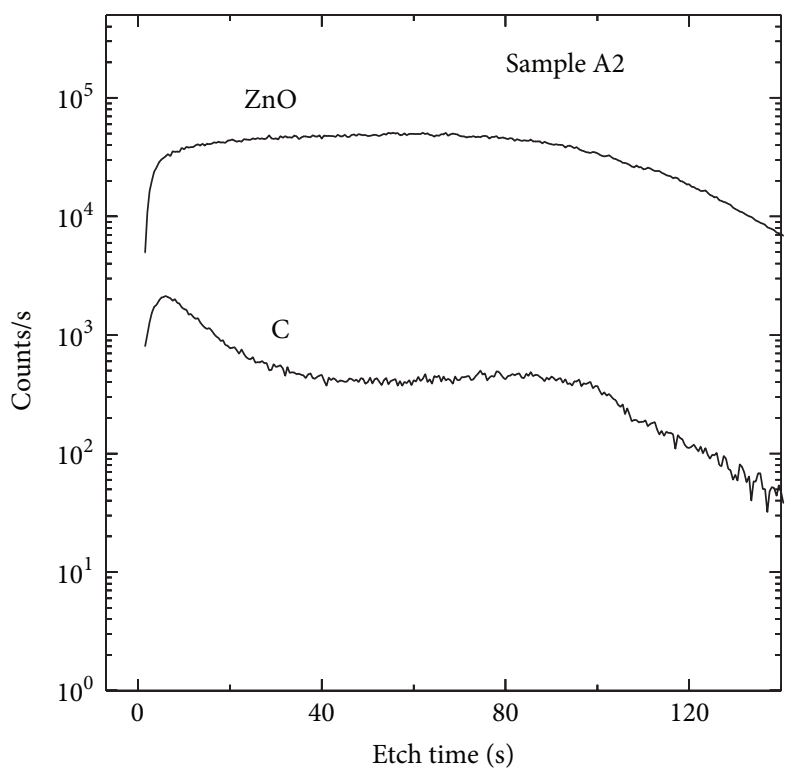

(a)

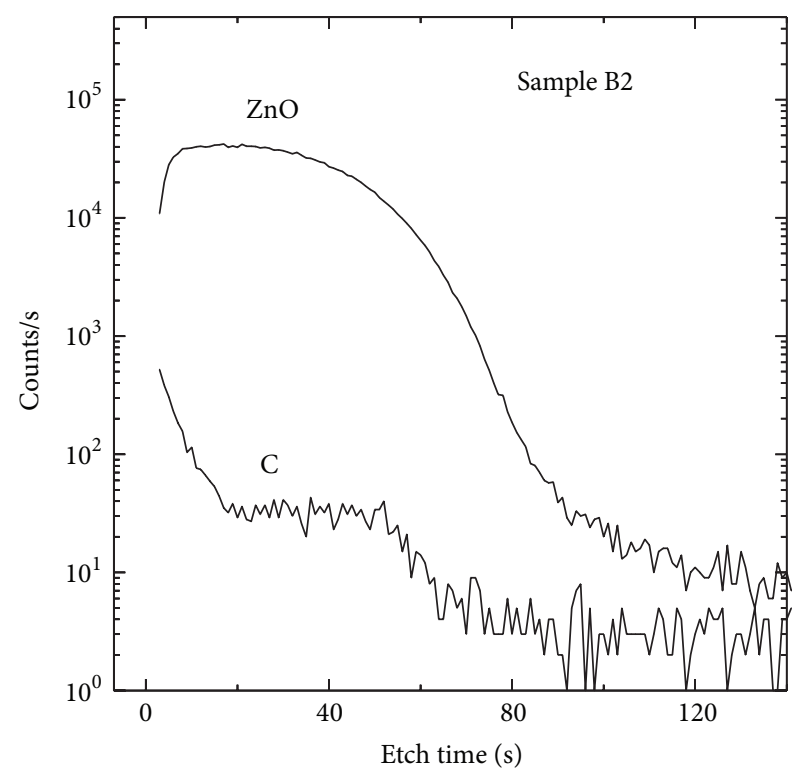

(b)

FIGURE 2: Secondary ion mass spectroscopy (SIMS) profiles measured in samples A2 and B2.

For sample $\mathrm{C}$ constant voltage of $-70 \mathrm{~V}$ was applied. After $\mathrm{ZnO}$ growth, $\mathrm{CO}_{2}$ flow was closed, and $\mathrm{O}_{2}$ flow of $4 \mathrm{sccm}$ was introduced during cool-down for complete oxidation of deposited films.

Thickness of $\mathrm{ZnO}$ films measured by X-ray reflectivity method was between $10 \mathrm{~nm}$ and $20 \mathrm{~nm}$. TFTs were fabricated by evaporating $\mathrm{Al}$ through a shadow mask. A tungsten wire of $25 \mu \mathrm{m}$ diameter placed on top of $\mathrm{ZnO}$ film separated the evaporated $\mathrm{Al}$ to make source and drain contacts. Figure $1(\mathrm{~b})$ shows a schematic diagram of a bottom-gate TFT structure. Postannealing was done at $400^{\circ} \mathrm{C}$ in gas flows of $5-\mathrm{sccm} \mathrm{O} \mathrm{O}_{2}$ and $5-\mathrm{sccm} \mathrm{CO}_{2}$, at $20 \mathrm{~Pa}$ pressure. Currents were measured by using Keithley 2400 source meters.

\section{Results and Discussions}

In Figure 2, we showed secondary ion mass spectroscopy (SIMS) profiles measured in samples A2 and B2. The carbon concentration in sample A2 is 10 times higher than that of sample B2. It is evident that the $\mathrm{CO}_{2}$ oxidizer used in sample A2 caused the higher carbon concentration.

Figures 3 and 4 show currents measured in a ZnO TFT grown with $\mathrm{CO}_{2}$ oxidizer and substrate voltage modulation (samples A1, A2). Figure 3(a) is drain currents measured at $10-\mathrm{V}$ drain-source voltage. Figure $3(\mathrm{~b})$ is drain currents measured while gate voltage was changed with $10-\mathrm{V}$ steps. In this figure, sample Al shows $4.7 \mathrm{~cm}^{2} /$ Vsec mobility, $4 \times 10^{6}$ on/off ratio, and $-2 \mathrm{~V}$ threshold voltage. Threshold voltage was extrapolated from the square root of drain current in Figure 3(a). Figure 4 shows currents measured in sample A2. Threshold voltage of sample A2 is more negative, and we think that it is due to the defects associated with higher gas flows used for the A2 growth.
In Figures 5 and 6, we compare current characteristics of $\mathrm{ZnO}$ TFT grown with $\mathrm{CO}_{2}$ and with $\mathrm{O}_{2}$. Dashed lines represent currents measured in $\mathrm{CO}_{2}$ grown sample (A1), and solid lines are data of $\mathrm{O}_{2}$ grown samples (B1, B2). As shown in the figures, the samples grown in $\mathrm{CO}_{2}$ atmosphere exhibit larger drain currents compared to those grown in $\mathrm{O}_{2}$. Furthermore, samples A1 and A2 have higher on/off ratio and smaller subthreshold swing value ( $S$-value), compared to samples B1 and B2. From these results, we suppose that $\mathrm{ZnO}$ grown in $\mathrm{O}_{2}$-rich condition has higher defect density or trap density, which is similar to that discussed in [4]. There can be many possibilities to explain the difference, such as increased n-type doping by the carbon or modification of grain boundary structure. It is also possible that more oxygen is adsorbed at the grain boundaries of $\mathrm{O}_{2}$ grown sample. Sample B2 shows lower currents than sample B1, due to the higher gas flows used for the growth.

In Figure 7, we compared current characteristics of TFT grown with the $1 \mathrm{~min}$ voltage modulation (sample A2) and with $-70 \mathrm{~V}$ constant voltage (sample C). Both samples were grown under the same growth conditions, except the substrate voltage modulation. In the figure, on-current of sample A2 is larger than that of sample C, while off-currents show similar behavior. We think that the voltage modulation contributed to the increase of on-current. Although sample A2 shows good mobility, the threshold voltage is $-10 \mathrm{~V}$, which can make only depletion-type TFT. Sample A1 in Figure 3 shows more positive threshold voltage, and it can be related to the lower gas flow and lower rf power used for the growth.

We investigated the thickness of $\mathrm{ZnO}$ films by $\mathrm{X}$-ray reflectivity (XRR). Thickness of sample A2 was around $18 \mathrm{~nm}$, as shown in Figure 8. We suppose that the bad fitting in the vicinity of low angle comes from the nonuniform film morphology by high substrate temperature during growth. 


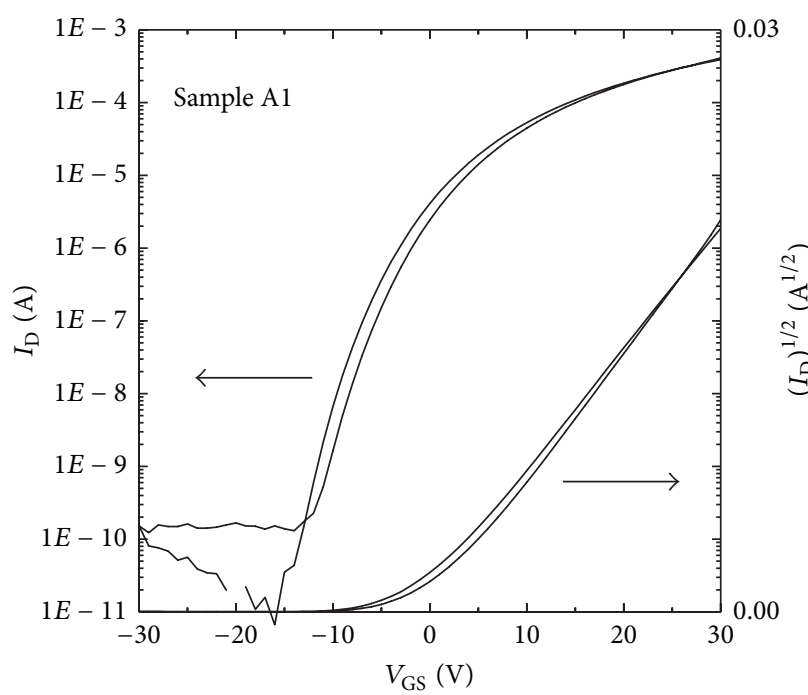

(a)

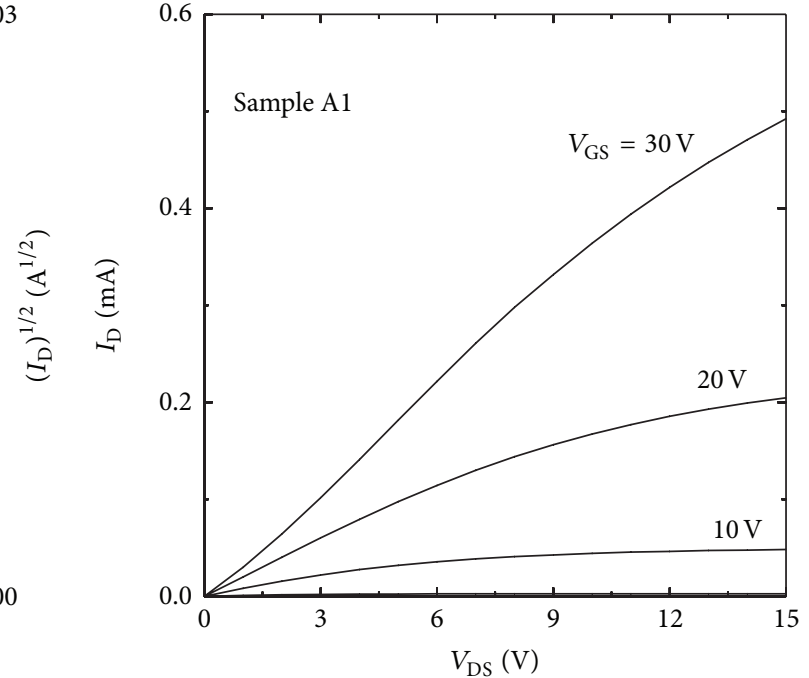

(b)

FIGURE 3: (a) Drain currents (log scale and square root) of ZnO TFT (sample Al) measured at $V_{\mathrm{DS}}=10 \mathrm{~V}$. (b) Drain currents for gate voltages of 30 to $-10 \mathrm{~V}$, with a $10-\mathrm{V}$ step.

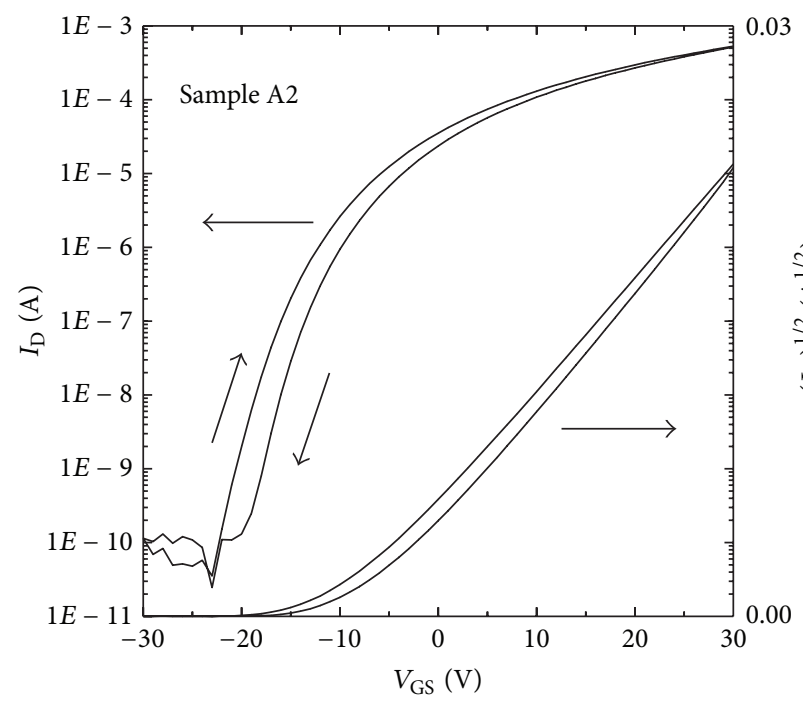

(a)

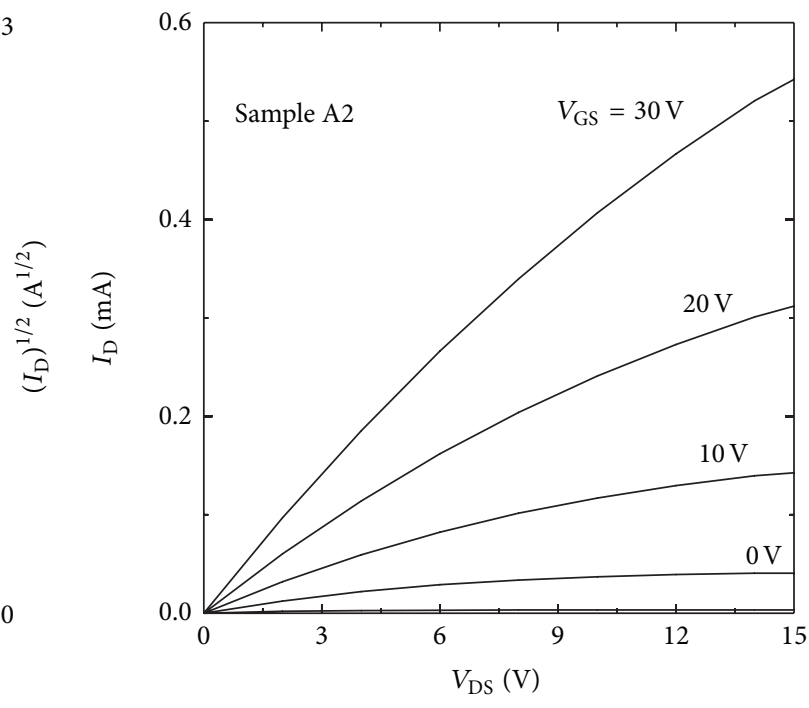

(b)

FIgURE 4: (a) Drain currents of sample A2 measured at $V_{\mathrm{DS}}=10 \mathrm{~V}$. (b) Drain currents for gate voltages of 30 to $-10 \mathrm{~V}$, with a $10-\mathrm{V}$ step.

We also investigated the crystalline structures of sample A2 by X-ray diffraction (XRD) using out-of-plane configuration. In Figure 9, we compared the as-deposited sample and the annealed sample, respectively. Both samples exhibited only hexagonal (002) diffraction around $34.4^{\circ}$ The difference between two samples was not so large; the full width at halfmaximum value changed from 0.84 to $0.80^{\circ}$. It is well known that the $c$-axis of the $\mathrm{ZnO}$ film tends to grow perpendicularly to the plane of the substrate. Therefore, hexagonal (002) diffraction results reflect the film thickness [22]. We expect that lateral grain size increased by postannealing. We think that the XRD peaks are weak because the films are too thin $(\sim 20 \mathrm{~nm})$. Crystal structure improves significantly when the layer thickness grows beyond a certain thickness. It appears that our films are thinner than that thickness. Our XRD result indicates that it is not necessary to have good crystal quality for good TFT currents.

There is a report that a growth mode transition was observed from a two-dimensional (2D) continuous mode to a three-dimensional (3D) island-like mode when the film is grown beyond a critical thickness [23]. In their explanation, films grown in a 2D mode are highly strained, and after a certain thickness, the film relaxes to a 3D configuration of lower energy. It is possible that the repeated switching of 


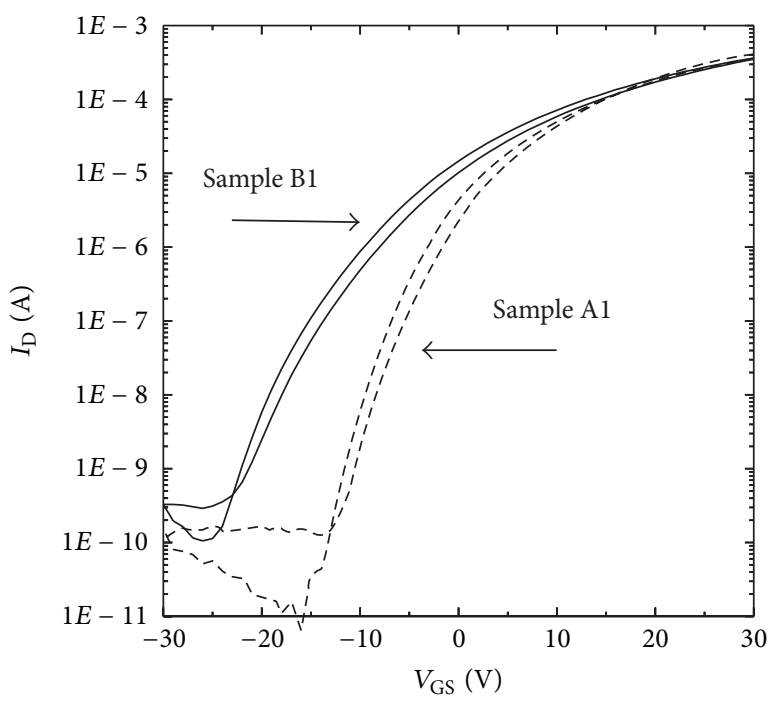

(a)

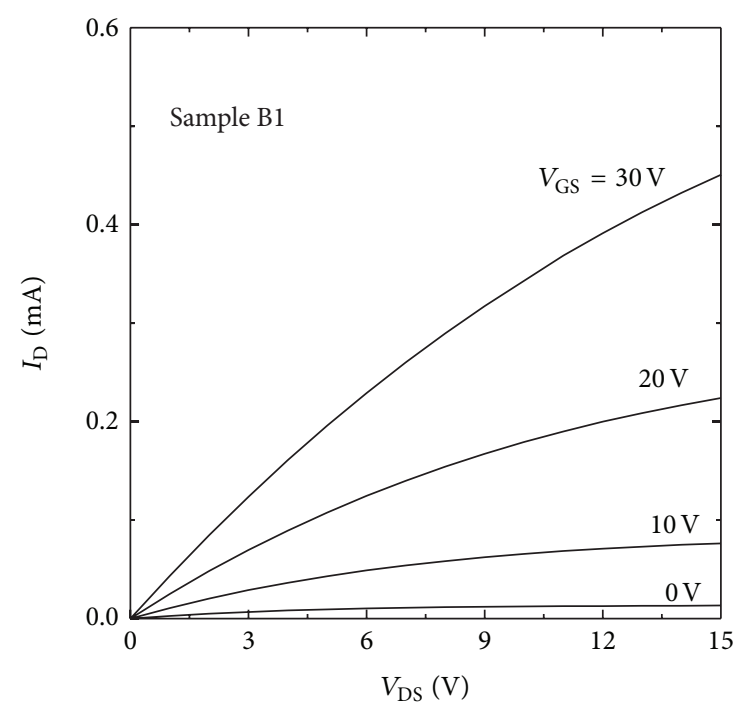

(b)

Figure 5: (a) Drain currents of samples A1 (dashed line) and B1 (solid line), measured at $V_{\mathrm{DS}}=10 \mathrm{~V}$. (b) Drain currents of sample B1 as a function of drain voltage. Sample Al was grown with $\mathrm{CO}_{2}$ and sample $\mathrm{B} 1$ with $\mathrm{O}_{2}$.

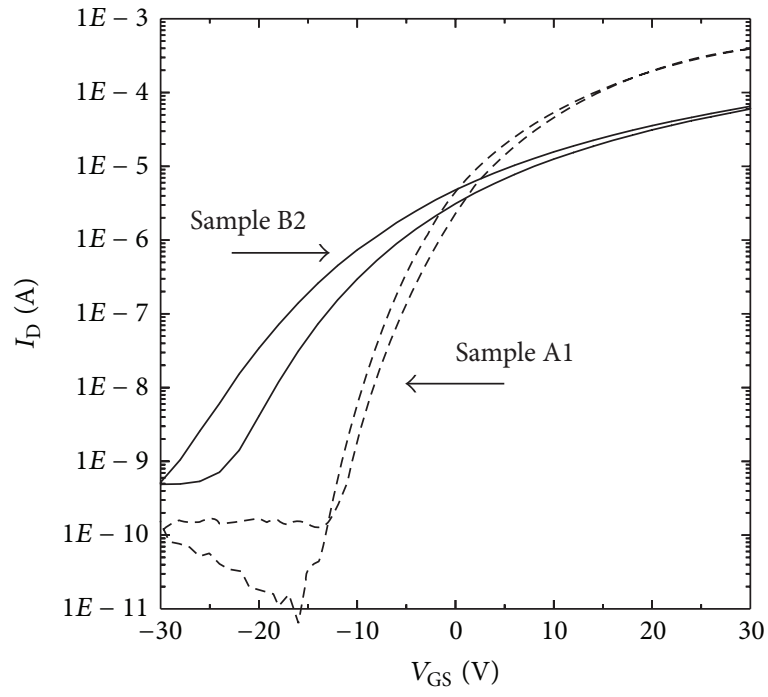

(a)

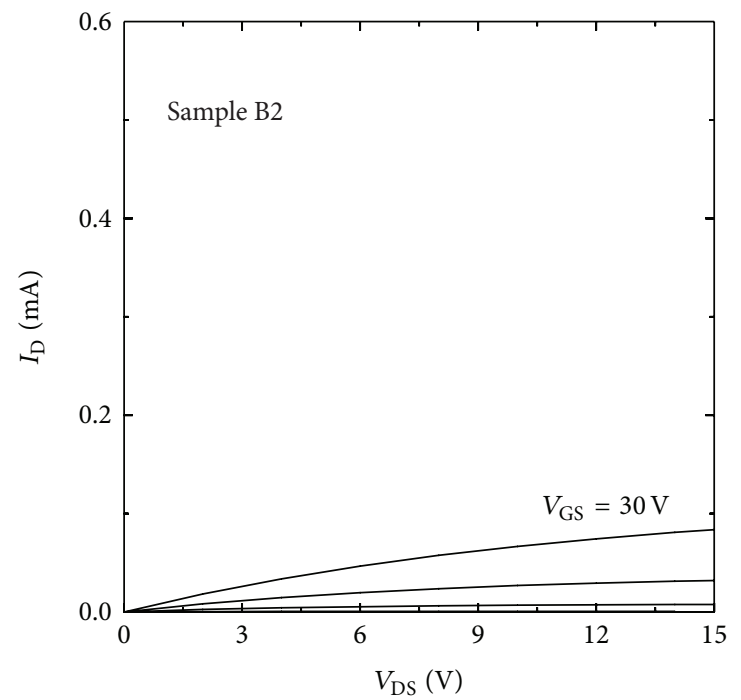

(b)

Figure 6: (a) Drain currents of samples A1 (dashed line) and B2 (solid line). Sample B2 was grown with $\mathrm{O}_{2}$. (b) Drain currents of sample B2 as a function of drain voltage.

substrate voltage in our sputtering growth could interrupt the transition into the $3 \mathrm{D}$ growth mode. More analysis is needed to clarify this point.

All of the currents shown in this paper were measured in air. Storage in air for a few days did not cause any difference in the currents. Storage in air for a long time (a few months) caused the threshold voltages shift to negative voltage. It appears that water adsorbed at the grain boundaries of $\mathrm{ZnO}$ increases electron density, and negative voltage shift is observed [8].

\section{Conclusion}

We demonstrated that $\mathrm{Ar} / \mathrm{CO}_{2}$ atmosphere and substrate bias modulation during sputtering growth improved characteristics of $\mathrm{ZnO}$ TFT. Our results showed that $\mathrm{CO}_{2}$ can be a good oxidizer for $\mathrm{rf}$ sputtering growth of $\mathrm{ZnO}$. Our results also showed that $\mathrm{CO}_{2}$ improves turn-off characteristics, compared to the $\mathrm{O}_{2}$ grown TFT. Substrate bias modulation contributed to the increase of on-current. We believe that the better TFT characteristics in $\mathrm{CO}_{2}$ grown $\mathrm{ZnO}$ are related to a lower 


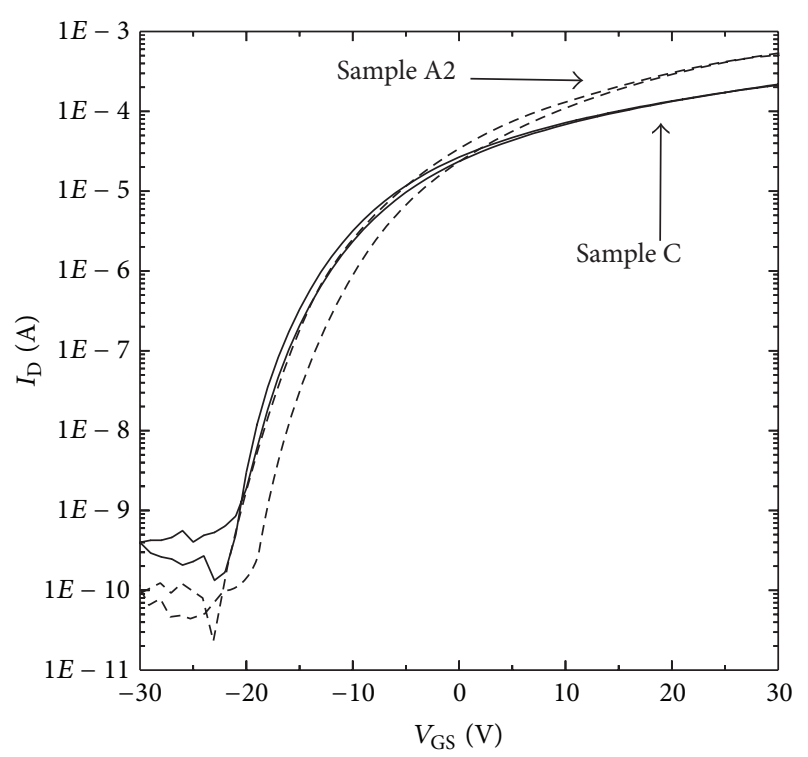

FIGURE 7: Drain currents of samples A2 (dashed line) and C (solid line), measured at $V_{\mathrm{DS}}=10 \mathrm{~V}$. Sample A2 was grown with the substrate bias modulation, and sample $\mathrm{C}$ was grown at $-70 \mathrm{~V}$ constant voltage.

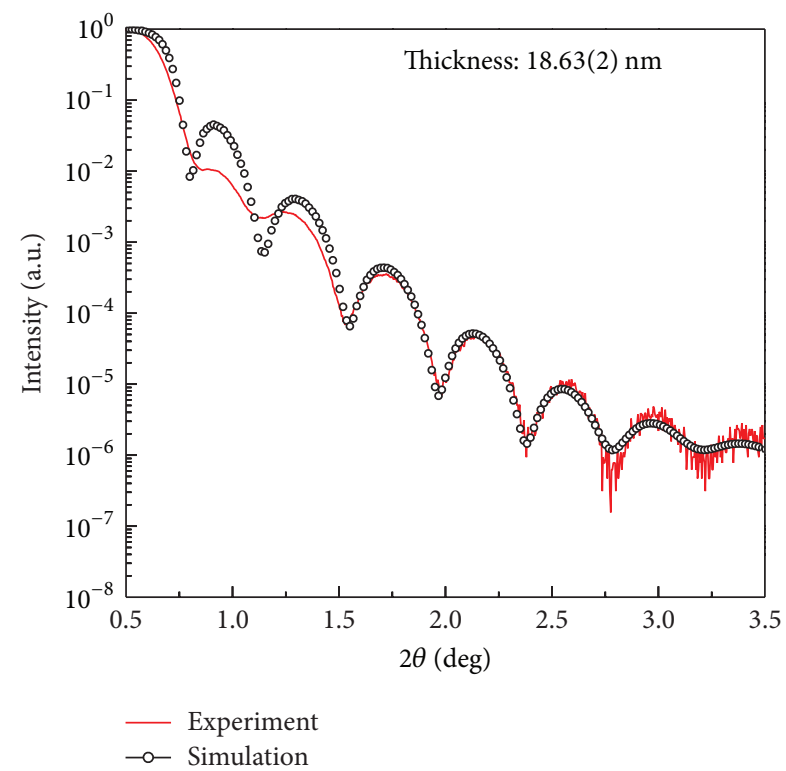

FIGURE 8: X-ray reflectivity (XRR) results of sample A2, deposited at $450^{\circ} \mathrm{C}$.

defect density, because $\mathrm{O}_{2}$ is more likely to produce defects due to the strong oxygen-oxygen bond.

\section{Conflict of Interests}

The authors declare that there is no conflict of interests regarding the publication of this paper.
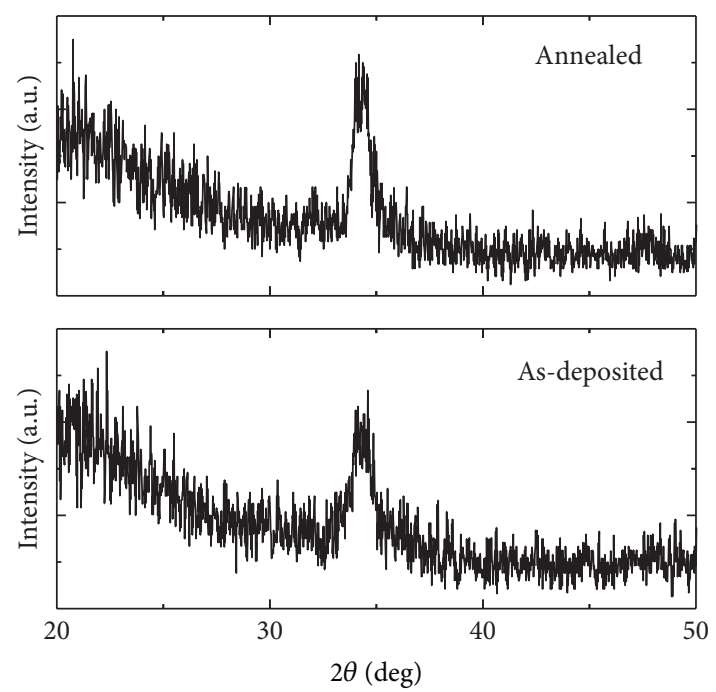

FIGURE 9: X-ray diffraction (XRD) patterns measured in sample A2, as-deposited and annealed.

\section{Acknowledgments}

The authors thank Eun-Ho Lee and Dukwon Lee of the Center for Material Characterization at Ajou University for $\mathrm{X}$-ray diffraction and scanning electron microscope measurements.

\section{References}

[1] M. Ito, M. Kon, C. Miyazaki et al., "Amorphous oxide TFT and their applications in electrophoretic displays," Physica Status Solidi (A) Applications and Materials Science, vol. 205, no. 8, pp. 1885-1894, 2008.

[2] T. Kamiya, K. Nomura, and H. Hosono, "Present status of amorphous InGaZnO thin-film transistors," Science and Technology of Advanced Materials, vol. 11, no. 4, Article ID 044305, 2010.

[3] S. Li, Y. Cai, D. Han et al., "Low-temperature ZnO TFTs fabricated by reactive sputtering of metallic zinc target," IEEE Transactions on Electron Devices, vol. 59, no. 9, pp. 2555-2558, 2012.

[4] P. F. Carcia, R. S. McLean, M. H. Reilly, and G. Nunes Jr., "Transparent $\mathrm{ZnO}$ thin-film transistor fabricated by rf magnetron sputtering," Applied Physics Letters, vol. 82, no. 7, pp. 1117-1119, 2003.

[5] E. Fortunato, P. Barquinha, A. Pimentel et al., "Wide-bandgap high-mobility $\mathrm{ZnO}$ thin-film transistors produced at room temperature," Applied Physics Letters, vol. 85, no. 13, pp. 25412543, 2004.

[6] K. Miyamoto, M. Sano, H. Kato, and T. Yao, "Effects of $\mathrm{ZnO}$ / $\mathrm{MgO}$ double buffer layers on structural quality and electron mobility of $\mathrm{ZnO}$ epitaxial films grown on c-plane sapphire," Japanese Journal of Applied Physics, Part 2: Letters, vol. 41, no. 11A, pp. L1203-L1205, 2002.

[7] J. Siddiqui, E. Cagin, D. Chen, and J. D. Phillips, "ZnO thin-film transistors with polycrystalline (Ba,Sr) $\mathrm{TiO}_{3}$ gate insulators," Applied Physics Letters, vol. 88, no. 21, Article ID 212903, 2006.

[8] J. Jo, H. Choi, J. Yun, H. Kim, O. Seo, and B. Lee, "Improvement of on/off ratio in $\mathrm{ZnO}$ thin-film transistor by using growth 
interruptions during metalorganic chemical vapor deposition," Thin Solid Films, vol. 517, no. 23, pp. 6337-6340, 2009.

[9] G. Adamopoulos, A. Bashir, S. Thomas et al., "Spray-deposited Li-doped $\mathrm{ZnO}$ transistors with electron mobility exceeding $50 \mathrm{~cm}^{2} / \mathrm{Vs}$," Advanced Materials, vol. 22, no. 42, pp. 4764-4769, 2010.

[10] H. Yabuta, M. Sano, K. Abe et al., "High-mobility thin-film transistor with amorphous $\mathrm{InGaZnO}_{4}$ channel fabricated by room temperature rf-magnetron sputtering," Applied Physics Letters, vol. 89, no. 11, Article ID 112123, 2006.

[11] P. S. Xu, Y. M. Sun, C. S. Shi, F. Q. Xu, and H. B. Pan, "The electronic structure and spectral properties of $\mathrm{ZnO}$ and its defects," Nuclear Instruments and Methods in Physics Research, Section B: Beam Interactions with Materials and Atoms, vol. 199, pp. 286290, 2003.

[12] A. F. Kohan, G. Ceder, and D. Morgan, "First-principles study of native point defects in ZnO," Physical Review B-Condensed Matter and Materials Physics, vol. 61, no. 22, pp. 15019-15027, 2000.

[13] X. Li, S. E. Asher, S. Limpijumnong et al., "Unintentional doping and compensation effects of carbon in metal-organic chemicalvapor deposition fabricated $\mathrm{ZnO}$ thin films," Journal of Vacuum Science and Technology A: Vacuum, Surfaces and Films, vol. 24, no. 4, pp. 1213-1217, 2006.

[14] J. W. Park, D. H. Kim, S.-H. Choi, M. Lee, and D. Lim, “The role of carbon doping in ZnO," Journal of the Korean Physical Society, vol. 57, no. 6, pp. 1482-1485, 2010.

[15] P. Erhart, A. Klein, and K. Albe, "First-principles study of the structure and stability of oxygen defects in zinc oxide," Physical Review B-Condensed Matter and Materials Physics, vol. 72, no. 8, Article ID 085213, 2005.

[16] E. Rühl and R. Flesch, "Mechanism of anion formation in C $1 s \rightarrow \pi^{*}$-excited carbon dioxide," Journal of Chemical Physics, vol. 121, no. 11, pp. 5322-5327, 2004.

[17] J. Jia, Y. Torigoshi, and Y. Shigesato, "In situ analyses on negative ions in the indium-gallium-zinc oxide sputtering process," Applied Physics Letters, vol. 103, no. 1, Article ID 013501, 2013.

[18] M. C. Chu, J. S. Meena, P. T. Liu et al., "Oxygen plasma functioning of charge carrier density in zinc oxide thin-film transistors," Applied Physics Express, vol. 6, no. 7, Article ID 076501, 2013.

[19] Y. Kawamura, N. Hattori, N. Miyatake, and Y. Uraoka, "Comparison between $\mathrm{ZnO}$ films grown by plasma-assisted atomic layer deposition using $\mathrm{H}_{2} \mathrm{O}$ plasma and $\mathrm{O}_{2}$ plasma as oxidant," Journal of Vacuum Science and Technology A: Vacuum, Surfaces and Films, vol. 31, no. 1, Article ID 01A142, 2013.

[20] K. Nomura, T. Kamiya, H. Ohta, M. Hirano, and H. Hosono, "Defect passivation and homogenization of amorphous oxide thin-film transistor by wet $\mathrm{O}_{2}$ annealing," Applied Physics Letters, vol. 93, no. 19, Article ID 192107, 2008.

[21] F. M. Hossain, J. Nishii, S. Takagi et al., "Modeling and simulation of polycrystalline $\mathrm{ZnO}$ thin-film transistors," Journal of Applied Physics, vol. 94, no. 12, pp. 7768-7777, 2003.

[22] J. Kim, H. Hiramatsu, H. Hosono, and T. Kamiya, "Fabrication and characterization of $\mathrm{ZnS}:(\mathrm{Cu}, \mathrm{Al})$ thin film phosphors on glass substrates by pulsed laser deposition," Thin Solid Films, vol. 559, pp. 18-22, 2014.

[23] S. I. Park, T. S. Cho, S. J. Doh, J. L. Lee, and J. H. Je, "Structural evolution of $\mathrm{ZnO} /$ sapphire(001) heteroepitaxy studied by real time synchrotron x-ray scattering," Applied Physics Letters, vol. 77, no. 3, pp. 349-351, 2000. 

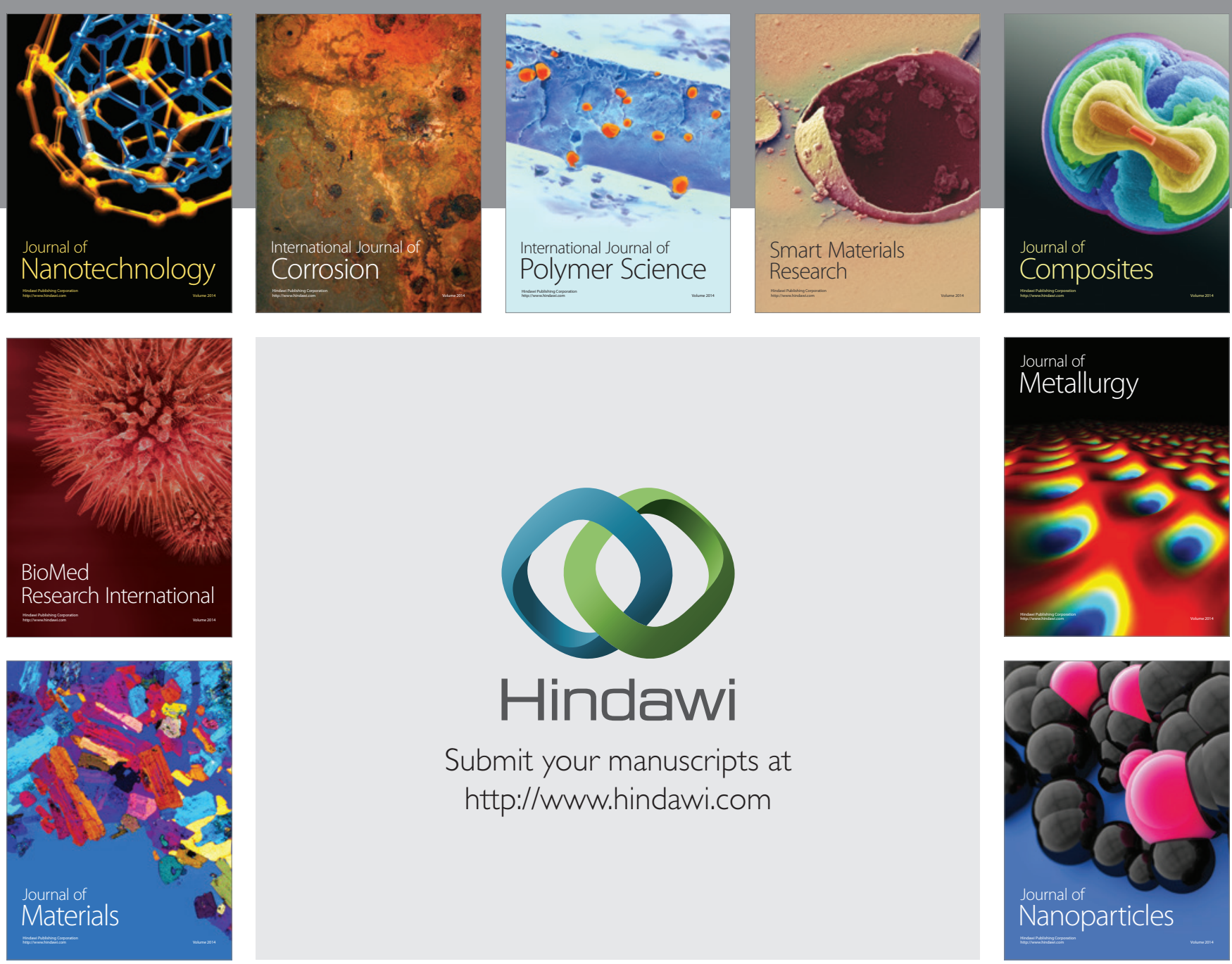

Submit your manuscripts at http://www.hindawi.com
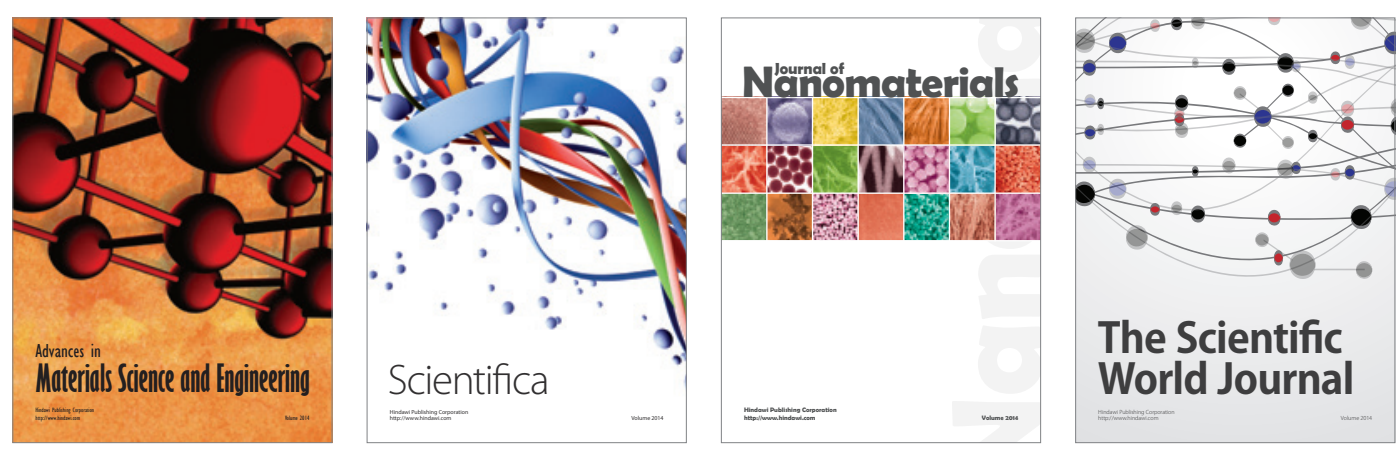

\section{The Scientific World Journal}
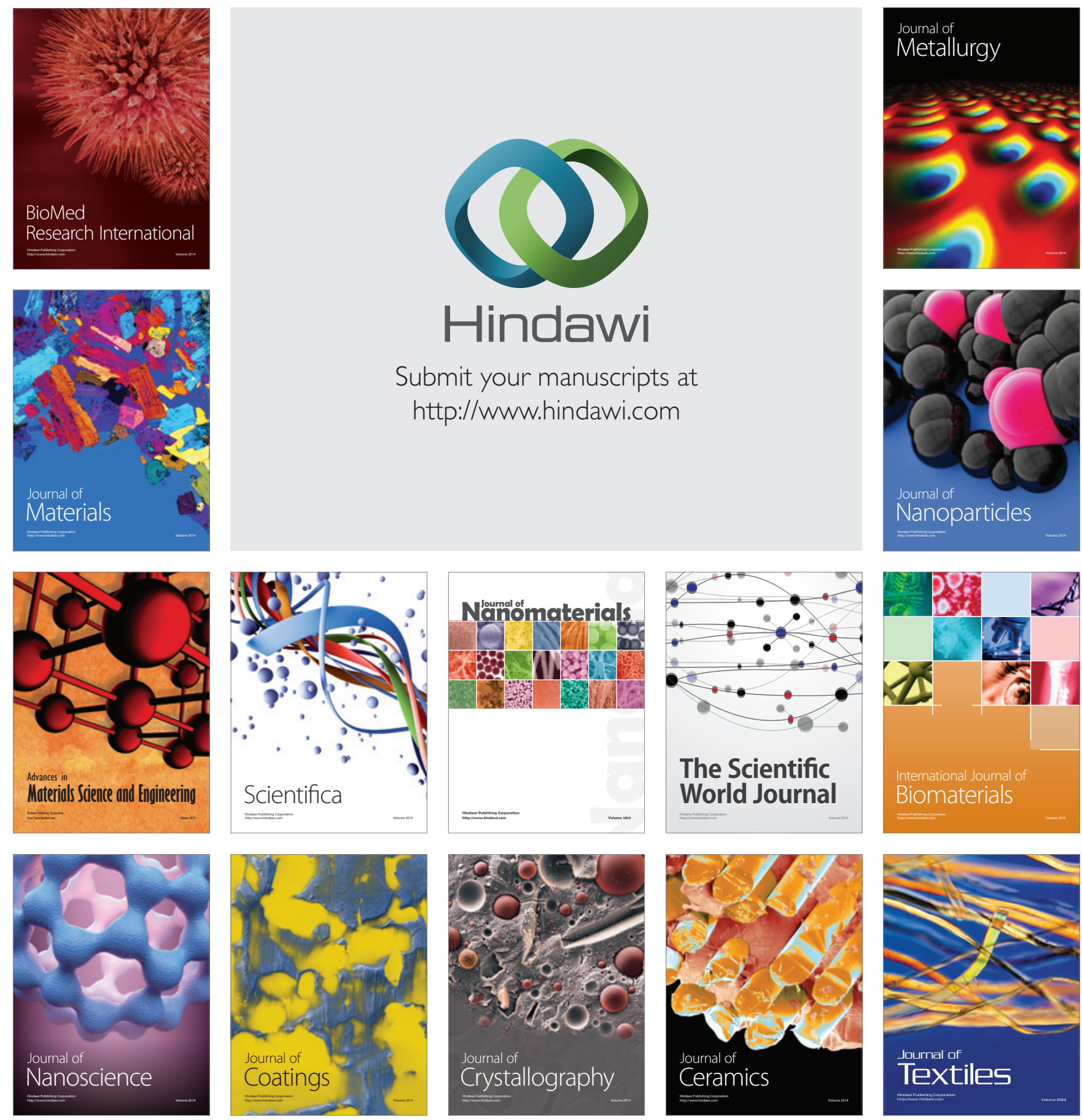